\title{
School Dropout and its Relationship with Quality of Primary Education in Nepal
}

\author{
Binay Kumar Kushiyait, Ph D \\ Reader, Central Department of Education, T.U. Kirtipur \\ bkushiyait@gmail.com
}

\begin{abstract}
The post-Jomtien period has witnessed a rising concern in the quality of primary education. This paper attempts to examine the quality of primary education and its association with the incidence of dropout from schools School survey form was administered to collect the necessary information from seventy two schools in Doti and Rautahat districts of Nepal. The significant indicators of dropout from schools are Toilet for girls, adequate teachers, committed and motivated teachers in profession, primary school curriculum, use of local teaching materials, 90+ pass rates, parental support to school, 90+ student attendance rates and regular school supervision by DEO. These indicators are found statistically significant with regard to the dropout rate as grouping variable. Therefore, dropout was found low in good quality schools with relatively better separate toilet for girls, adequate teachers, school having curriculum and teaching materials, and provision of 90 percent and above attendance rate of students.
\end{abstract}

Key Words: Dropouts, Retention, Quality education, Quality school, The Mann-Whitney Rank Sum U test, Binary Logistic Regression.

\section{Context}

There are two broad critical stages in the development of the primary education system in a country. The first is the stage of expansion in schooling opportunities for children to enhance their equitable access to and retention in school. With growth in access, equity and retention, the system enters into the second stage with expressed concern in the quality of education delivered while maintaining the pace of expansion as well. In the case of Nepal, during the earlier three decades, from 1950 to 1980, Government policies and programmes in primary education seemed to be more driven by the characteristics of the first stage, i.e. the stage of expansion of opportunities. One great example of key thirst in the quantitative expansion can be found in the National Education System Plan (1971-1975) which even reduced the span of primary education from five to three years with a view to showing a spectacular increase in the rate of enrolment in the primary school system. So, as in many other countries, prior to the Jomtien Conference (1990), much of the emphasis in Nepal was placed on quantitative goals such as increasing the number of children enrolled in school. But the post-Jomtien period has witnessed a rising concern in the quality of primary education. Political and educational 
leaders became increasingly mindful of the fact that "enhanced access in the absence of quality instruction is a hollow victory" (UNESCO, 2000). The Basic and Primary Education Programme (BPEP) Phase I and II, which dominated the pattern of the growth of primary education in Nepal during the 1990's, had many components geared to enhancing the quality of primary schools in the country. After the Dakar Conference of 2000, the focus in quality of education has further sharpened. The Education for All (E) Action Plan (2001-2015), EFA 2004-2009 Sector Programme of Nepal and School Sector Reform Plan (SSRP) 2009-15 aims to ensure equitable access to quality primary education for all.

\section{Coceptual Framework}

It is difficult to precisely define and measure the concept of 'quality education'. Discussing this problem of defining 'quality' in an acceptable manner, Beeby (1979) has suggested that 'quality' may be viewed as qualitative change which can further be defined as a simple linear expansion or diminution of current practice, more or less, of what already exists: more buildings, more students and teachers fewer examinations of the present type and standards. The qualitative change is further differentiated in terms of (a) qualitative change in classroom- what is taught and how it is taught; (b) qualitative change in the flow of students- who is taught and where he/she is taught. Thus Beeby has defined school quality in a dynamic perspective, focusing on the actors and actions involved in school functioning rather than the passive material inputs available in the school. In general, the definition of quality education is related with student outcomes. Many educators also include the nature of educational experience and the learning environment that help to produce those outcomes (Ross and Lars, 1990). According to UNESCO, quality education must be supported by the four pillars of learning: learning to know, learning to do, learning to be and learning to live together (UNESCO, 1996).

Discussing the concept of quality education, Mukhopadhyay (2005) states that quality education implies comprehensibly developing individuals to their full potential, unfolding the 'perfection already on man' (and women). The challenge of management of quality in education is realizing optimally that perfection already resident in individuals, not only among students but also among teachers, non-teaching staff, and principals. The importance is on the quality of life in institutions where a student is shaped and teachers and others spend the primes of their lives.

Quality education embraces different aspects of education. One important landmark of quality is the goal of education itself. The quality education has to take into consideration the broader goals of the development of an individual in the context of the purpose of school education. Likewise, 'quality education' has also been depicted in terms of its impact on the individual and the society. The most prominent contention is that the school effectiveness is the indicator of quality. For instance, the percentage of students who graduate from a school and the proportion of students getting higher levels of achievement are the most popular indicators of school effectiveness. This offers a limited opportunity to us to see school effectiveness as a comprehensive indicator of quality (UNESCO, 1996). Since school is the most important formal place where the process of education takes place, it is said that school quality plays a crucial role in delivering quality education.

A quality primary school has to meet two important conditions: first, it has to necessarily meet the specifications of inputs and processes set as quality benchmarks, and second, the school 
should provide a good learning environment through such behavioural factors like motivated teachers and students, high staff morale, school-community relationships, and strong leadership (Mukhopadhyay, 2005). As viewed by Dakar Frame of Action (DFA), quality education is the one that satisfies basic learning needs, and enriches the lives of learners and their overall experience of living. Thus, the quality of education is defined in terms of learning environment in a school and student outcomes. A wide variety of policies and inputs, tailored to specific conditions, can bring about effective schooling. The EFA document states:

A successful quality education programme requires : (a) healthy, well-nourished and motivated students; (b) well-trained teachers and active learning techniques; (c) adequate facilities and learning materials; (d) relevant curriculum that can be taught and learned in a local language and that builds upon the knowledge and experience of the teachers and learners; (e) an environment that not only encourages learning but is welcoming, gender sensitive, healthy and safe; (f) clear definition and accurate assessment of learning outcomes, including knowledge, skills, attitudes and values; (g) participatory governs and management; and (h) respect for and engagement with local communities and cultures (UNESCO, 2000).

According to Fuller (1985), educational quality is defined in terms of the amount of material inputs assigned to schools per student, and the level of efficiency with which a given amount of inputs is organized and administrated in order to improve the students' learning achievement. This definition emphasizes the aggregate contribution of the school to the academic achievement of the student, independently of pre-school background, community context, and child labour. It is stated that distribution of educational opportunities is to be understood as the allocation of sufficient educational inputs in order to ensure retention, advancement and relevant learning among all the pupils in a given educational system. Quality of education allows for looking at school characteristics and interaction between school and its environment, and to relevant learning outcomes (UNESCO, 1996).

\section{Material and Methods}

The objective of this paper is to examine the quality of primary education and its association with the incidence of dropout from schools. For this purpose, the quality of 72 surveyed schools is determined in terms of selected criteria relating to physical facilities, quality of teachers and head teachers, use of teaching learning materials, learning environment at school, student, teacher and school support system, school management, and parent-school relationship; and then, the relationship between the school quality and the magnitude of dropout. On the basis of the attributes of a quality primary school so far identified, the quality of 72 survey schools from Doti (Hill) and Rauthat (Tarai) district are assessed. Among them 46 schools were selected from Doti and 26 from Rautahat district. . Both the Hill and the Tarai districts were purposively sampled for this study. However, the basis for the selection of Doti and Rautahat districts was the survival rate in primary education. The Hill district with a municipality and recording the lowest survival rate in primary education among the hill districts and the Tarai district with the lowest survival rate in primary education. This study seeks to establish the relationship between the quality of 72 schools and their dropouts with comprehensive level because national status of all schools of Nepal is almost the same. 
The study area $\mathrm{t}$ is located in the central Tarai and far western Nepal (Map 1).

Map .1

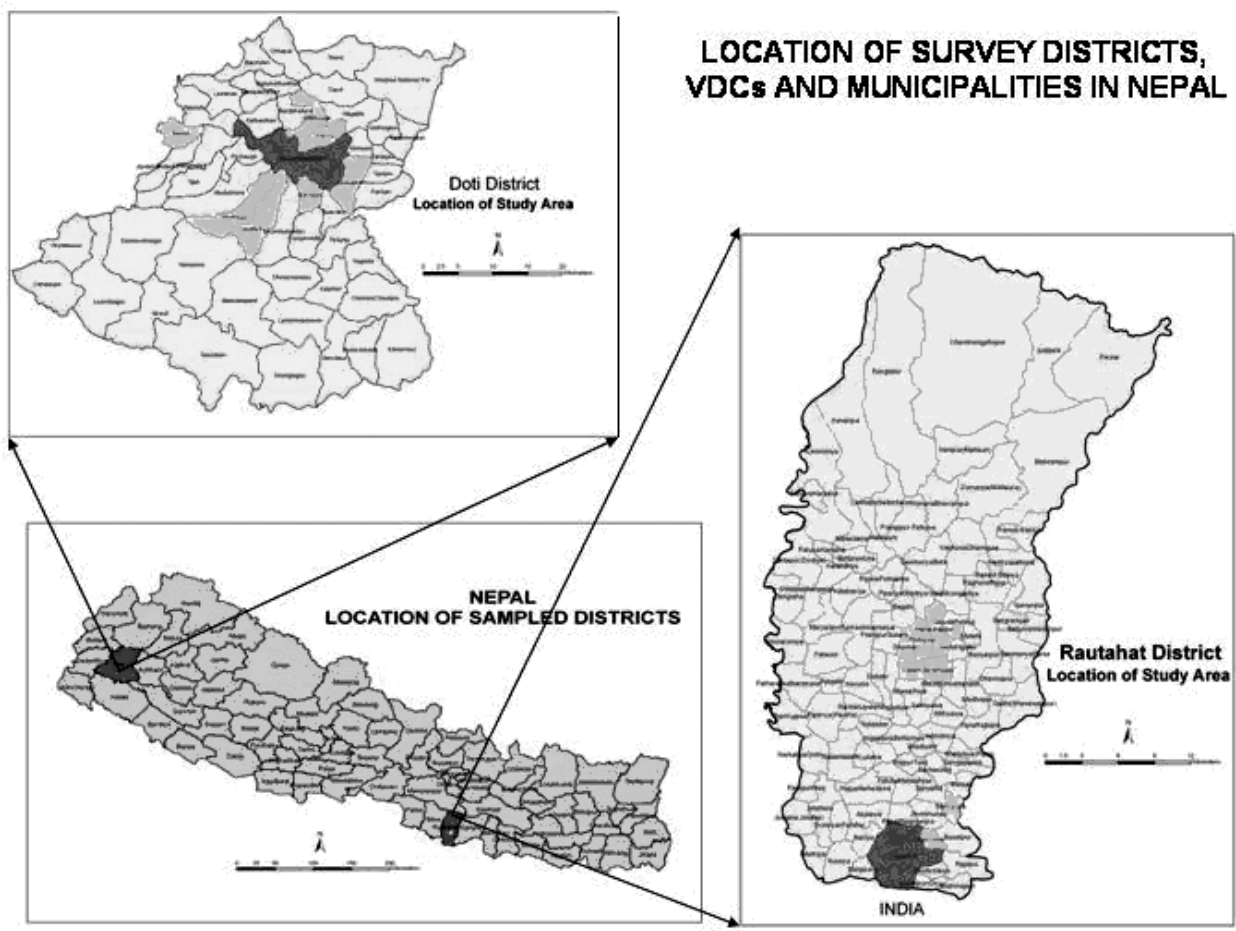

What determines the quality of a primary school in the Nepalese context? In order to answer this question, the researcher developed a checklist of attributes of a good primary school based on a synthesis of literature reviewed and using his own insights and experiences. This checklist was circulated among 50 persons with relevant knowledge and expertise in the field of primary education including key officials of the Department of Education (DOE), District Education Officers, School Supervisors, Resource Persons, Teachers, Head teachers, Teacher trainers, Educationists, Education Policy Makers, Education Planners, Professors, and Researchers in education. All of them were requested to review the checklist and mark each item in the list as essential, or important, or optional for a quality primary school in the context of Nepal. On the basis of their responses, all items marked essential were picked up to prepare a net list of the attributes of a good primary school. This list was later incorporated into the school survey form. On the basis of the responses, a list of essential qualities of a good primary school was drawn and carried out to examine the relationship between dropout and their variables such as essential qualities of a good primary school The most reported essential quality of school were classified into eleven broad headings such as Physical facilities, Teacher, Head Teacher, Instructional materials, Learning Environment of Schools, Extra-curricular activities, School community relationship, Student, Teacher and School support system and School management. 


\section{Relationship Between School Quality and Dropout in Primary Schools}

Schooling means not only the number of children who go to school and stay there; it is also concerned with learning in a good manner. So, apart from accessibility, the quality of school is concerned more with the teaching of valuable skills. A quality school plays a vital role to enhance learning environment by availability and performance of different factors such as basic facilities, child friendly teaching learning methods, co-curricular activities, development of teacher and school support system, school management and school-community relationship.

Role of quality education is fostering student's cognitive, moral and social development; and it is a preparation for world of work (societal needs). Quality primary education focuses on knowledge and skills that are universally accepted. As opined by Kellaghan and Vencent (2001), the test of school quality is answered by such questions as: "Can student read? Can they write? Can they compute? Have they an understanding of basic scientific concepts?" Without quality schools, the achievement of these qualities may not be made. The most emphasized indicators of quality schooling is related with student performance (e.g. good learning levels of children), followed by teacher- related indicators such as teacher's experience, regularity and dedication and school-related factors such as adequate physical facilities and good management. A good quality school is required to possess such minimal conditions as trained/motivated teachers, adequate physical facilities, regular teaching, and useful curriculum. When the school has quality and functions well, children's motivation to attend school is created and sustained. It helps to reduce dropout and enhance retaining capacity of school on the one hand, while, on the other, it also helps to produce many valued outcomes of schooling relating to attitude, values, aspirations, and motivation of students. Therefore, if the quality of learning is the heart of 'Education for All', the role of school is vital in creating a safe, attractive and supportive environment for children and, thereby, in enabling a primary education system to achieve the EFA goals.

The ultimate goal of the universal primary education is to attain universal access to, and completion of primary education by all children of primary school age group. This goal is concerned not only with expansion of access to primary education to cover all eligible children, but also with improvement in quality, so that all children enrolled actually complete the primary cycle. In this context, only quality school helps to create good learning environment in school.

What determines the quality of a primary school in the Nepalese context? In order to answer this question, the researcher developed a checklist of attributes of a good primary school based on a synthesis of literature reviewed and using his own insights and experiences. Statistical tests were carried out to examine the relationship between dropout and other variables. As the data used in the analysis are in the lower scale of measurement most of the parametric statistical tests would become inapplicable. Hence, the nonparametric test of Mann-Whitney Rank Sum $\mathrm{U}$ and Binary Logistic Regression has been used.

\section{The Mann-Whitney Rank Sum $U$ test}

It was highly desirable to test the possible association between dropout rate and other categorical variables like the adequacy of class room and toilet for girls. For this, The Mann-Whitney Rank Sum $U$ test for the association was used. The Mann-Whitney Rank Sum $U$ test accomplishes essentially the same what a t-test does for the interval scale data in the parametric counterpart. For a two-sampled test, Mann-Whitney $U$, examines if the two samples deviates significantly 
from Normal distribution. For the two tailed significance test it uses the asymptotic distribution of the test statistics in place of a t-distribution or a Normal distribution as does the parametric tests. Typically, a value of less than 1.0 is considered significant. The asymptotic significance is based on the assumption that the data set is larger than 30 . If the data set is small or poorly distributed, this may not be a good indication of significance.

It is seen from the table given below that although many indicators on the frequency count show a disproportionate value for one of the category the Mann-Whitney $U$ signals only nine of the indicators as significant. The significant indicators are: Toilet for girls, adequate teachers, committed and motivated teachers in profession, primary school curriculum, use of local teaching materials, $90+\%$ pass rate, parental support to school, $90+\%$ student attendance and regular school supervision by DEO. These indicators are found statistically significant with regard to the dropout rate as grouping variable.

For Value of Mann-Whitney $U$ statistics for indicators analysed by the dropout code as grouping variable see Annex 1 (the bold faced indicators are significant).

\section{Binary Logistic Regression}

As we have set of dichotomous indicator variables and we wish to examine the extent of relationship exerted from these indicator variables on rate of dropout the ordinary least square (OLS) technique will be inapplicable. The most appropriate regression technique in this situation will be the Binary Logistic Regression. This method can regress more powerfully a dichotomous dependent variable on a set of independent variables than other analysis such as discriminate analysis (Darlington, 1990; Anderson 1980; Welkowitz, Ewen \& Cohen, 1991). Binary Logistic Regression is useful for situations in which we want to predict the presence or absence of a characteristic or outcome based on values of a set of predictor variables. It is similar to a linear regression model but is suited to models where the dependent variable is dichotomous. Logistic is different from OLS in the sense that, it uses response as an indicator of absence/presence $(0 / 1)$ of some characteristics. Logistic regression coefficients can be used to estimate 'odds ratios' for each of the independent variables in the model. Logistic regression is applicable to a broader range of research situations than discriminate analysis (Darren \& Paul, 2006).

First response variables, that is the dropout rate, were categorized as $1=$ above median (median value was about 7.11), and $0=$ below median. With this categorized response Binary Logistic Regression was run in SPSS with the set of indicator variables. Using method = Enter the following results were obtained.

Table 1: Significant Indicators from Binary Logistic Regression after 6th iteration

\begin{tabular}{clcccccc}
\hline SN & Indicators & B & S.E. & Wald & df & Sig. & Exp (B) \\
\hline 1 & Toilet for girls & 2.52 & 0.83 & 9.25 & 1 & 0.00 & 12.48 \\
2 & Adequate teachers & 2.74 & 0.88 & 9.62 & 1 & 0.00 & 15.41 \\
3 & Students with full text books & 2.08 & 1.09 & 3.67 & 1 & 0.06 & 8.04 \\
4 & Primary school curriculum & 1.54 & 0.77 & 4.04 & 1 & 0.04 & 4.66 \\
5 & CAS & -3.09 & 1.01 & 9.41 & 1 & 0.00 & 0.05 \\
6 & 90+ attendance & 2.66 & 1.28 & 4.31 & 1 & 0.04 & 14.30 \\
7 & Constant & -4.72 & 1.40 & 11.40 & 1 & 0.00 & 0.01 \\
\hline
\end{tabular}

Source: Field survey 
Although, we cannot interpret the B (beta) coefficient directly from Logistic Regression as will be for OLS, we can however construct a logarithm based model similar to the linear model as,

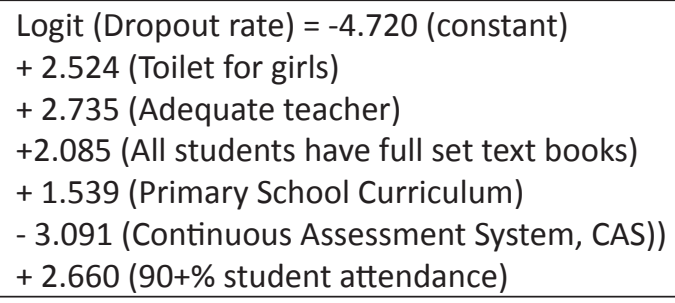

A logit function seen above is the natural logarithm (In) taken over the Odds ratio and is expressed as,

$$
\text { Logit }(\text { dropout })=\mathbf{h}(\text { Odds ratio })=\mathbf{h}\left(\frac{\mathbf{P}(\text { dropout }=1)}{\mathbf{P}(\text { dropout }=0)}\right)
$$

Hence, the above results can be interpreted accordingly. For example, the above analysis shows that toilet for girls (separate toilet) reduces the dropout rate about 2.5 times or in other words it can retain the students about 2.5 times higher. Similarly, adequate teachers $(5$ teachers or more) can improve the retention of students about 2.7 times higher or can reduce dropout to about 2.7 times higher. The significantly negative coefficient was observed only for CAS. It may be some other unseen factors associated with CAS that may have caused this strange result. Also, the EXP (B) values, shown above, can be useful as they give the odd ratio, or the ratio of the probability of happening to not happening.

Table 2: Model Summary up to 6th iteration

\begin{tabular}{ccc}
\hline Iteration Steps & $\mathbf{- 2}$ Log likelihood & Nagelkerke R Square \\
\hline 1 & 83.84 & 0.26 \\
2 & 75.27 & 0.38 \\
3 & 68.60 & 0.47 \\
4 & 63.10 & 0.53 \\
5 & 58.33 & 0.58 \\
6 & 54.11 & 0.63 \\
\hline
\end{tabular}

Source: Field survey

For the degree of fit of the model we can look at the Model Summary shown above. As Logistic is not a linear model we cannot calculate R-square directly as we can for OLS. However, tests like -2 Log likelihood produced by SPSS gives the pseudo R-squared statistics which are based on comparing the likelihood of the current model to the "null" model (one without any predictors). A larger pseudo R-square statistics indicate that more of the variation is explained by the model, from a minimum of 0 to a maximum of 1 . Here, at the 6 th iteration, we can find the pseudo $\mathrm{R}$-square value as high as 63 percent which is quite a good fit for such social data.

Interrelation Between Dropout Rate, Retention and Educational Environment The summary statistics were computed for dropout rate and various factors representing different educational environment. To quantify this interrelation, logistic regression was used. 
Methodology of this regression and the rational for its use were given above. The specific implications from the analysis are stated in the following points.

\section{Dropout Rate and Infrastructure}

Here infrastructure indicates a separate toilet for girls. It is seen that infrastructure has a slope coefficient (B) 2.52 which is significant below 1.0 percent level. These values indicated that schools with this infrastructure facility can retain students 2.5 times more than schools without such facility. In other words, it is likely that a school not having separate toilet for girls will have 2.5 times higher chance for dropout of a student.

\section{Dropout Rate and Teacher Facility}

Here, teacher facility indicates adequacy of teacher. It is seen that teacher facility has a slope coefficient (B) of 2.74 with significance below 1.0 percent. This indicates that a school with teacher facility is 2.74 times more likely to retain students than a school without such facility.

\section{Dropout Rate and Teaching Material}

Here, teaching material indicates to availability of full text book to students. It is found that teaching material has a slope coefficient (B) of 2.08 which is significant below 6 percent. At this slightly higher level, it is found that, about twice more likely, there will be dropout in a school without the facility of teaching learning material.

\section{Dropout Rate and School Curriculum}

The slope coefficient for school curriculum (B) is 1.5 which is significant at 4.0 percent level. It indicates that there is a positive relation between school curriculum and retention rate. Thus, a school having own curriculum is about 1.5 times more likely to retain students than a school not having curriculum.

\section{Dropout Rate and Continuous Assessment System (CAS)}

The slope coefficient (B) for CAS is negative with magnitude 3.09 which is significant at less than 1.0 percent level. Here the negative sign associated with CAS coefficient is unexplainable from this method as it indicates to a higher dropout associated with the provision of CAS. Hence, it suggests that some other hidden factors are associated with CAS.

\section{Dropout Rate and Student Attendance}

Here, student attendance rate indicates a provision of 90 percent and above attendance rate of students. The slope coefficient for attendance (B) is 2.66 percent with significance level of 4 percent. This indicates that it is about 2.7 times more likely for school having 90 percent and above attendance rate of students to retain students compared to a school that has lesser percentage of attendance rates.

\section{Conclusion}

The discussion made in this paper clearly shows that there exists relationship between quality of school and students' dropout or retention in primary education. Major school-related factors such as teachers' absenteeism, irregular operation of school, lack of child-friendly environment in school and demotivating school environment as the causes of driving students away from school. It is seen that there exists convincing relationship between the quality of school and the magnitude of dropout or retention in primary education. The summary statistics were 
computed for dropout rate and various factors representing different educational environment. The statistical values indicated that schools with the infrastructure facility can retain students 2.5 times more than schools without infrastructure facility. In other words, it is likely that a school not having separate toilet for girls will have 2.5 times higher chance for dropout of a student. It is seen that teacher facility has a slope coefficient (B) of 2.74 with significance below 1.0 percent. This indicates that a school with teacher facility is 2.74 times more likely to retain students than a school without such facility. It is found that teaching material has a slope coefficient (B) of 2.08 which is significant below 6 percent. At this slightly higher level, it is found that, about twice more likely, there will be dropout in a school without the facility of teaching learning material. School having curriculum is about 1.5 times more likely to retain students than a school not having curriculum.

Here, student attendance rate indicates to a provision of 90 percent and above attendance rate of students. The slope coefficient for attendance (B) is 2.66 percent with significance level of 4 percent. This indicates that it is about 2.7 times more likely for school having 90 percent and above attendance rate of students to retain students compared to a school that has lesser percentage of attendance rates. In conclusion dropout was found low in good quality schools with relatively better separate toilet for girls, adequate teachers, school having curriculum and teaching materials, and provision of 90 percent and above attendance rate of students. It is thus established that there exists convincing relationship between the quality of school and the magnitude of dropout or retention in primary education.

\section{References}

Anderson, Theodore W. (1980). An introduction to multivariate statistical analysis. New York: Wiley.

Beeby, C.E. (1979). Assessment of Indonesian education: A guide in planning. Wellington: Council for Educational Research in Association with Oxford University Press.

Darlington Richard B.(1990). Regression and linear models. New York: McGraw Hill.

Darren, George \& Paul Mallery. (2006). SPSS for Windows Step by Step: A Simple Guide and Reference. New Delhi: Dorling Kindersley Pvt. Ltd. India.

Education World Forum. (2000). The Dakar framework for action. Paris: UNESCO.

Fuller, Bruce. (1985). Raising school quality in developing countries: What investments boost learning? Washington DC: The World Bank.

Kellaghan \& Vencent. (2001). Using Assessment to Improve the Quality of Education. Paris: International Institute for Educational Planning/UNESCO.

Ross, Kenneth N. and Lars Mahlck. (1990). Planning the Quality of Education: The Collection and Use of Data for Informed Decision Making. Paris: UNESCO.

Mukhopadhyay, M. (2005). Total quality management in education. New Delhi: SAGE Publication.

UNESCO. (1996). The quality of primary education: A case study of Puebla. Paris: International Institute for Educational Planning/UNESCO.

UNESCO. (2000). Education world forum final report. Dakar

Welkowitz, John; Ewen Robert and Cohen Jacob. (1991). Statistics for the behavioral science. New York: Harcourt Brace Jovanovich. 
Annex 1

Value of Mann-Whitney U Statistics for Indicators by the Dropout and Quality variables

\begin{tabular}{|c|c|c|c|}
\hline SN & Quality Variables & Mann-Whitney U & $\begin{array}{c}\text { Asymptotic } \\
\text { Significancy } \\
\text { (2-tailed) }\end{array}$ \\
\hline 1 & Adequate class room (5 or more) & 581 & 0.36 \\
\hline 2 & Adequate desk/bench in class room & 630.5 & 0.82 \\
\hline 3 & Toilet for girls & 364 & 0.00 \\
\hline 4 & Adequate teacher ( 5 or more) & 356 & 0.00 \\
\hline 5 & All full trained teachers (100\%) & 607 & 0.59 \\
\hline 6 & Teachers take class regularly & 580.5 & 0.21 \\
\hline 7 & $90+(\%)$ teacher attendance in school & 606.5 & 0.44 \\
\hline 8 & Teachers are represent in SMC & 549 & 0.13 \\
\hline 9 & Trained teachers & 549 & 0.13 \\
\hline 10 & $90+(\%)$ head teacher attendance in school & 608.5 & 0.36 \\
\hline 11 & Committed and motivated teachers in profession & 544.5 & 0.05 \\
\hline 12 & Training on primary school management & 575 & 0.35 \\
\hline 13 & Frequent meeting with parent & 566 & 0.21 \\
\hline 14 & Regular teacher meeting & 567 & 0.23 \\
\hline 15 & All students have full set text books & 606.5 & 0.44 \\
\hline 16 & Getting text books on time & 561.5 & 0.25 \\
\hline 17 & $\begin{array}{l}\text { Primary school curriculum (what availability or } \\
\text { coverage?? }\end{array}$ & 490.5 & 0.03 \\
\hline 18 & Use of local teaching materials & 555 & 0.02 \\
\hline 19 & School calendar & 543 & 0.17 \\
\hline 20 & Comfortable sitting arrangement in class room & 637.5 & 0.88 \\
\hline 21 & Continuous Assessment System (CAS) & 566.5 & 0.22 \\
\hline 22 & $90+\%$ pass rate & 463 & 0.01 \\
\hline 23 & Parent Teacher Association (PTA) & 545.5 & 0.08 \\
\hline 24 & Frequently meeting with parent and teacher & 569 & 0.27 \\
\hline 25 & $\begin{array}{l}\text { Parents frequently visit in School and discuss } \\
\text { their wards' performance with teachers }\end{array}$ & 598.5 & 0.51 \\
\hline 26 & Parental support to school & 412.5 & 0.00 \\
\hline 27 & Individual attention to student & 586 & 0.32 \\
\hline 28 & $90+\%$ student attendance & 562 & 0.09 \\
\hline 29 & Regular home work & 639.5 & 0.90 \\
\hline 30 & $\begin{array}{l}\text { Professional support by School supervisor, } \\
\text { Resource person and Head teacher }\end{array}$ & 602.5 & 0.50 \\
\hline 31 & School based refresher training & 606.5 & 0.44 \\
\hline 32 & Regular School supervision by DEO & 430 & 0.00 \\
\hline 33 & Budget release on time & 592.5 & 0.47 \\
\hline 34 & School Management Committees (SMC) formed & 610.5 & 0.14 \\
\hline
\end{tabular}

Source: Field survey 